\title{
TRACKING TRAJECTORY OF THE MOBILE ROBOT KHEPERA II USING APPROACHES OF ARTIFICIAL INTELLIGENCE
}

\author{
Peter ŠUSTER, Anna JADLOVSKÁ \\ Department of Cybernetics and Artificial Intelligence, Faculty of Electrical Engineering and Informatics, \\ Technical University of Košice, Letná 9, 04200 Košice, Slovak Republic, tel.: +421 55602 4214, \\ e-mail: peter.suster@tuke.sk, anna.jadlovska@tuke.sk
}

\begin{abstract}
This paper introduces a solution to the reference trajectory tracking problem done by a differential wheeled mobile robot Khepera II. The paper includes a kinematic part and a dynamic part of the mathematical model of mobile robot. In this paper two approaches of the artificial intelligence are used i.e. genetic algorithm approach from evolutionary computing techniques and theory of neural networks. Genetic algorithm is used for parameters optimizing PID controller and K parameter so-called parameter speed of rotation at the tracking reference trajectory into defined control structure. For the creation forward and inverse neural model by the approach of neural networks are used forward neural networks of MLP type. The neural models are verified using Neural Network Toolbox. The forward neural model of the mobile robot is implemented into the IMC control structure together with the inverse neural model, which is used as a nonparametric neural controller. The purpose of the designed control structure is tracking the defined trajectory of the mobile robot using approaches of the artificial intelligence, which are verified by the simulations in the language Matlab/Simulink.
\end{abstract}

Keywords: mobile robot, MLP neural network, forward neural model, inverse neural model, genetic algorithm, tracking trajectory

\section{INTRODUCTION}

The mobile robots are used for different applications in various branches of industries. The primary task for every mobile robot is to move along a defined trajectory. To ensure that mobile robot moves along the reference trajectory it is possible to use the predictive control approach [4] or can devise neuro-fuzzy controller [7]. In our paper we have decided to apply for the task of tracking entered reference trajectory approaches of the artificial intelligence (AI) - evolutionary computing techniques and theory of neural networks. Evolutionary computing techniques (ECT) are increasingly used for solving of optimization tasks. In this paper ECT are used for parameter optimization of the PID controller and the parameter speed of rotation $\mathrm{K}$ which they ensure that mobile robot tracks the reference trajectory. Another approach of the AI, which is used in this paper, is forward neural networks of MLP type, [13]. Neural networks are able to model of nonlinear dynamic systems without knowing their internal structure and physical description. Training data necessary to obtain nonparametric neural controller are received from designed control structure, which ensures the movement of model of mobile robot along the predefined trajectory, [3]. The simulation model of kinematics and dynamics of mobile robot, which is used for verifying the proposed algorithms of tracking reference trajectory, is based on real mobile robot Khepera III of K-Team Corp. [5]. The paper is organized as follows. Part two includes a mathematical model of the mobile robot, which consists of kinematic and dynamic parts. Part three contains a control of the mobile robot into defined control structure using PID control, whose parameters are calculated by using genetic algorithm. There the process of devise of the genetic algorithm from definition of the individuals in the generation to resulting graphs of tracking defined trajectory is mentioned. In part four tracking trajectory of the mobile robot using theory of neural networks is solved. There is a design of the forward and inverse neural models, which are implemented into IMC structure, which allows to tracks the defined trajectory of mobile robot.

\section{MATHEMATICAL MODEL OF MOBILE ROBOT KHEPERA II}

The created a model is based on several assumptions, namely that the robot moves on a perfect flat surface without sliding and also neglects the rolling resistance of the wheels. Position of the mobile robot is given by the coordinates $x, y$ and angle $\theta$, which represents the rotation of the mobile robot in relation to the chosen coordinate system. Mobile robot is controlled by the angular velocities of the wheels $\omega_{L}, \omega_{R}$. Between the angular velocities $\omega_{L}, \omega_{R}$ and peripheral speeds $v_{L}, v_{R}$ there are the following relations

$v_{L}=r \omega_{L}, v_{R}=r \omega_{R}$

where $r$ is radius of the wheel. Position and rotation of the robot in the space can be based on the following equations, which form a kinematic model of the mobile robot (Fig. 1)
$\dot{x}(t)=v \cos \theta$ $v=\frac{v_{L}+v_{R}}{2}$
$\dot{y}(t)=v \sin \theta \Rightarrow$
$\dot{\theta}(t)=\omega$
$\omega=\frac{v_{L}-v_{R}}{b}$

where the inputs into the kinematic model are speeds wheels $v_{L}$ resp. $v_{R}$ and the outputs are $x, y, \theta$. The kinematic model (Fig. 1) allows us to determine the position and rotation of the robot under the condition that we know the initial state of the robot and we have updated information about the speed of the individual wheel. 


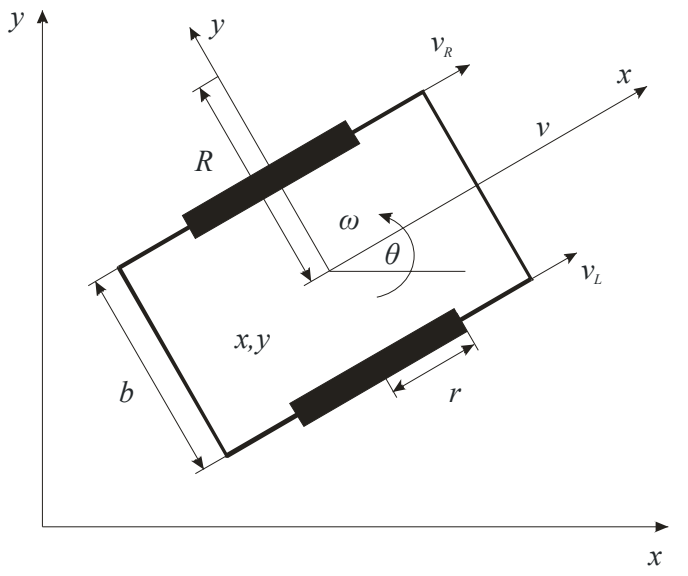

Fig. 1 Kinematic model of mobile robot

The kinematic model does not include friction forces acting on the wheel and the total mass of the mobile robot, so we have extended the mathematical - physical model about the dynamic part (Fig. 2), which has the following form:

$$
\begin{aligned}
& m a_{t}=F_{L}+F_{R} \\
& J \varepsilon=\frac{\left(F_{L}-F_{R}\right) b}{2}
\end{aligned}
$$

where tangent acceleration $a_{t}$ is given by mass of the robot $m$ and tangent forces $F_{L}$ and $F_{R}$, acting on the wheels due to changes in the rotation speed [6]. Angular acceleration $\varepsilon$ is determined by the same forces, the moment of inertia of the robot $J$ and distance between the wheels $b$ (3). Angular velocities $\omega_{L}$, and $\omega_{R}\left(\omega_{L}=\dot{\theta}_{L}, \omega_{R}=\dot{\theta}_{R}\right)$ of the mobile robot are driven by the voltage $U_{L}$ and $U_{R}$. Differential equations expressing this fact have the following form:

$$
\begin{aligned}
& J \ddot{\theta}_{L}(t)+F_{T} \dot{\theta}_{L}(t)+F_{L} r=U_{L} \\
& J \ddot{\theta}_{R}(t)+F_{T} \dot{\theta}_{R}(t)+F_{R} r=U_{R}
\end{aligned}
$$

where $F_{L}$ is friction force acting on the wheel [1]. From equations (3) and (4), we have obtained a dynamic model of the mobile robot in the state space:

$$
\begin{aligned}
& \dot{x}(t)=A x(t)+B u(t) \\
& y(t)=C x(t)
\end{aligned}
$$

where the state variables and their derivates have the following physical meaning:

$$
\begin{aligned}
& x(t)=\left[x_{1}(t), x_{2}(t), x_{3}(t), x_{4}(t)\right]=\left[v(t), \omega(t), \omega_{L}(t), \omega_{R}(t)\right] \\
& \dot{x}(t)=\left[\dot{x}_{1}(t), \dot{x}_{2}(t), \dot{x}_{3}(t), \dot{x}_{4}(t)\right]=\left[a_{t}(t), \varepsilon(t), \varepsilon_{L}(t), \varepsilon_{R}(t)\right]
\end{aligned}
$$

and inputs into the system of mobile robot are:

$$
u=\left[u_{1}(t), u_{2}(t), u_{3}(t), u_{4}(t)\right]=\left[F_{L}, F_{R}, U_{L}, U_{R}\right]
$$

and outputs from the system are:

$$
y(t)=\left[y_{1}(t), y_{2}(t)\right]=\left[x_{3}(t), x_{4}(t)\right] \text {. }
$$

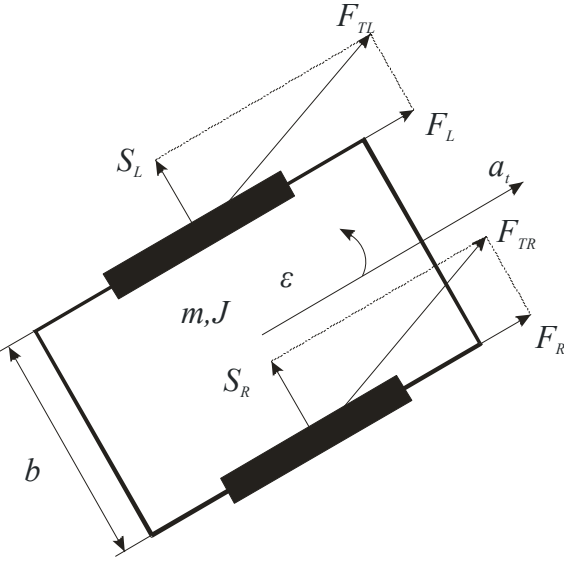

Fig. 2 Dynamic model of mobile robot

We programmed simulation scheme of the mobile robot (Fig. 3) as two subsystems in the Matlab/Simulink language, based on the equations of the kinematics (2) and dynamics model (3) (4) [8]:

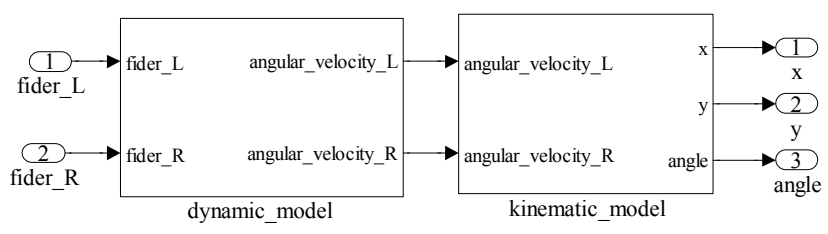

Fig. 3 Simulation scheme of mobile robot - kinematics

We proposed a control structure to ensure that the mobile robot can track one of the set reference trajectories (Fig. 4). The inputs into control structure of model robot are coordinates of the current position of model robot real $\mathrm{x}$, real $\mathrm{y}$ and coordinates of reference trajectory reference $\mathrm{x}$, reference $\mathrm{y}$. The Euclidean distance between current and desired position of the model robot is calculated by means of these coordinates. The outputs from control structure are angular velocities for the left and the right wheels (fider_L, fider_R).

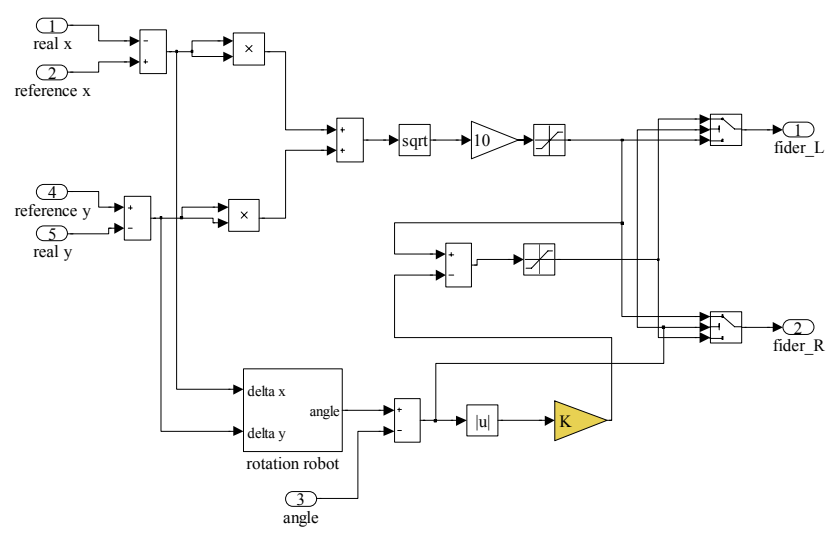

Fig. 4 Simulation scheme of the control structure

The mathematical model of the mobile robot together with proposal control structure, is used to verify suitability parameter $\mathrm{K}$ and parameters of PID controller for left and right wheel of mobile robot designed by genetic algorithm (Fig. 5) and also it is used to obtain training data for design forward and inverse neural model [8]. 


\section{TRACKING REFERENCE TRAJECTORY OF THE MOBILE ROBOT USING GENETIC ALGORITHM}

In this paper we used to track reference trajectory of the mobile robot Khepera II approaches of AI i.e. evolutionary computing techniques and neural networks. The most important and the most widely used ECT are genetic algorithms, which are used to solve optimization tasks related with optimal setting parameters of the systems [9].

In this part of paper are optimized using genetic algorithm parameters of PID controller for left and right wheel and parameter speed of rotation $\mathrm{K}$ into defined control structure of cascade control (Fig. 5).

\subsection{Using genetic algorithm for tracking reference trajectory of the mobile robot Khepera}

Genetic algorithm deals with optimization or the potential solutions (genes, strings) in the population, which are subject to reproduction. The process of reproduction consists of the following three basic operations [10]:

- selection of chromosomes

- crossing of chromosomes

- mutation of chromosomes

Reproduction of population improves her features, on the basis of evaluation of chromosomes by so-called fitness function. In the process of resolving the GA global maximum of fitness function is searched, i.e. to find the best solution to a given problem.

In this part of the paper, GA serves for proposing parameters of PID controller and parameter of speed of rotation $\mathrm{K}$, which is used to control structure, to control of mobile robot Khepera II during the tracking defined reference trajectory.

Numbers of individuals in one population, is considered fixed and consists of parameters of PID controller and parameter of speed of rotation $\mathrm{K}$, so the final share of generation is: $\{\mathrm{P}, \mathrm{I}, \mathrm{D}, \mathrm{K}\}$.

Before starting with solving the task, it is needed to set ranges of parameters $\mathrm{P} \in\left(\mathrm{P}_{\mathrm{MIN}}, \mathrm{P}_{\mathrm{MAX}}\right), \quad \mathrm{I} \in\left(\mathrm{I}_{\mathrm{MIN}}, \mathrm{I}_{\mathrm{MAX}}\right)$, $\mathrm{D} \in\left(\mathrm{D}_{\mathrm{MIN}}, \mathrm{D}_{\mathrm{MAX}}\right), \mathrm{K} \in\left(\mathrm{K}_{\mathrm{MIN}}, \mathrm{K}_{\mathrm{MAX}}\right)$. For evaluation of suitability of generations is used the Euclidean distance between the reference and actual location of mobile robot during simulation. The formula for calculating the Euclidean distance has the following form:

$$
d=\sqrt{\sum_{k=1}^{N}\left(\Delta x_{k}^{2}+\Delta y_{k}^{2}\right)}
$$

\subsection{Verification of suitability of the proposed parameters}

The proposed genetic algorithm, which runs over a population of potential solutions $\{\mathrm{P}, \mathrm{I}, \mathrm{D}, \mathrm{K}\}$ is expressed by the following steps:

1. the coordinates of reference trajectory which are stored in the files $\left\{\mathrm{x}_{\mathrm{ref}}\right.$ mat, $\mathrm{y}_{\mathrm{ref}}$ mat $\}$ are introduced on the input of control structure,
2. the parameters of individuals of current generation $\{\mathrm{P}, \mathrm{I}, \mathrm{D}, \mathrm{K}\}$ are given in the simulation scheme (Fig. 5),

3. the coordinates of reference trajectory $\left\{\mathrm{x}_{\mathrm{ref}}, \mathrm{y}_{\mathrm{ref}}\right\}$ and current trajectory $\left\{\mathrm{x}_{\text {real }}, \mathrm{y}_{\text {real }}\right\}$ of model of mobile robot are stored in files into workspace of Matlab language,

4. these files are then used in calculating the suitability of the current generation parameters,

5. after verification of the individuals using Euclidean distance (6) the best individuals is selected and are applied for reproduction to current generation,

6. selection of parents is the first step in the process of reproduction. The selection of the parents is based on tournament selection,

7. the next step there is a single point crossover between the parents to obtain new individuals (children) to a new generation,

8. the final step is mutation of new individuals, in our case additive mutation is used,

9. after finishing the reproduction is tested condition of termination, which in our case given number of generations, if the condition is not fulfilled, then we return to step 2.

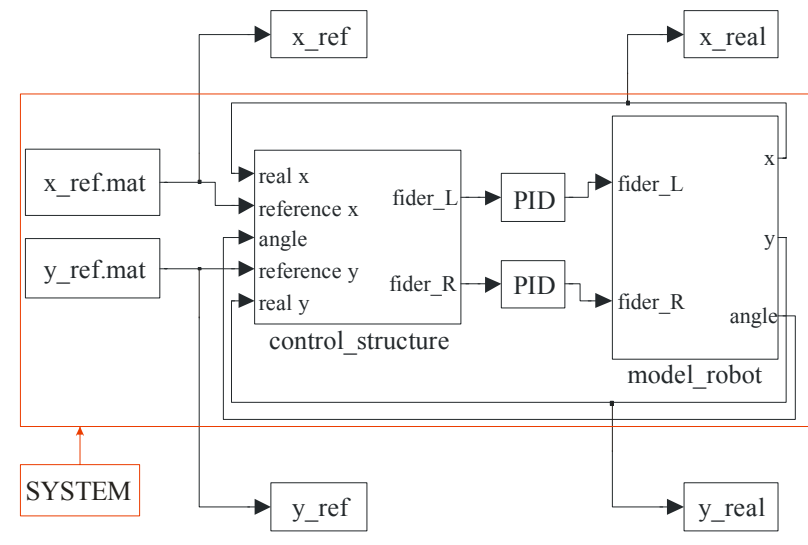

Fig. 5 Simulation scheme for verification of suitability of PID controller parameters and $\mathrm{K}$ parameter

Genetic algorithm for optimization of PID parameters and $\mathrm{K}$ parameter are applied for tracking of two types of reference trajectories - trajectory of shape a sinus and shape of an ellipse. The resulting trackings of the defined trajectory are shown in Fig. 6 and Fig. 7.

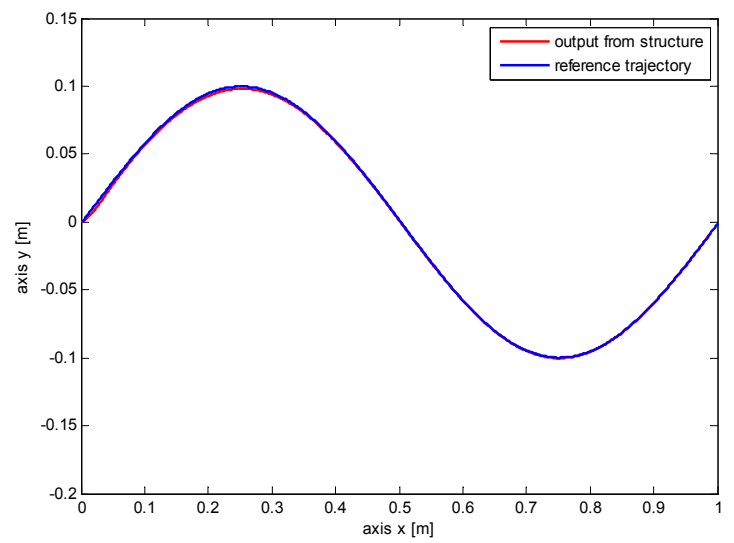

Fig. 6 Tracking defined reference trajectory of shape a function sinus 


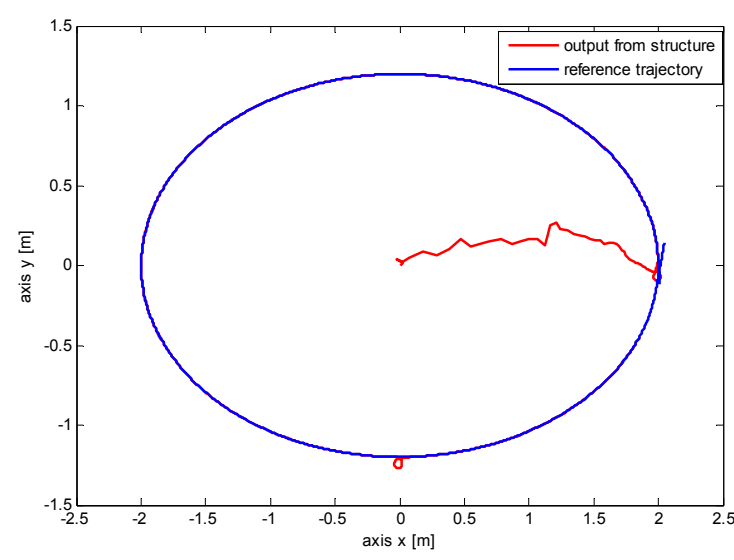

Fig. 7 Tracking defined reference trajectory of shape a ellipse

\section{TRACKING REFERENCE TRAJECTORY OF THE MOBILE ROBOT USING FORWARD NEURAL NETWORK}

In this section are used forward neural networks for tracking predefined reference trajectory of mobile robot. Neural networks with their universal approximation properties are capable to model and control nonlinear dynamic systems without mathematical and physical description. They use data entering and leaving from system, which represents dynamics of the system. Base on these training data using chosen optimization algorithm then adjusts synaptic weights of neural network. This process is called learning neural network. Thus correctly learned network can be then used to model and control almost any nonlinear dynamic system without hard nonlinearities, [3] [13].

In part three, we obtained, using of genetic algorithm PID controller parameters which ensured us that mobile robot tracked the defined reference trajectory in the proposed control structure of cascade control. In this part of paper the possibility of using neural network method for obtains the forward and inverse neural model of mobile robot is showed. In this case the inverse neural model represents nonparametric neural controller. These two obtained neural models are implemented into the Internal Model Control structure, which allows to track the defined trajectory of mobile robot, [12].

\subsection{Forward neural model of mobile robot}

The neural model, which approximates dynamics of the system is called forward model. Neural network is placed in parallel with identification system and error between output of the neural network $\hat{y}(k+1)$ and output of the dynamic system $y(k+1)$, the so-called prediction error, is used as training signal for neural network (Fig. 8).

If the output of the neural model is $\hat{y}(k+1)$ then we can express the equation by approximation

$$
\hat{y}(k+1)=\hat{f}[y(k), \ldots,(k-n+1), u(k), \ldots, u(k-m+1)]
$$

where $\hat{f}$ represents the nonlinear input-output representation by the neural model and $y(k)$ resp. $u(k)$ is $n$ -output resp. $m$ - input of the previous values [3].

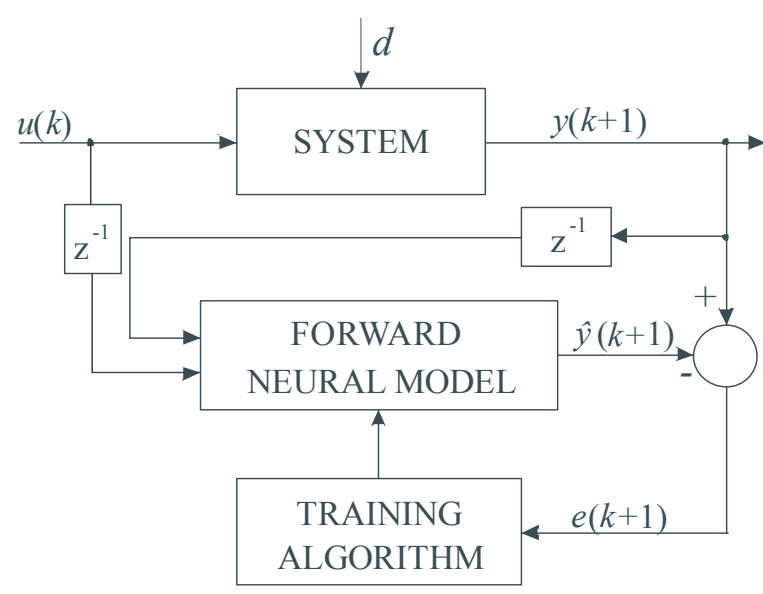

Fig. 8 Identification scheme based on output prediction error

Training data for proposal forward neural model are obtained from simulation scheme to simulate the movement of the robot along the defined reference trajectory. Reference trajectory is represented by vectors $\mathrm{x}$ and y coordinate. For training the forward neural model of mobile robot is used a forward neural network of Multi Layer Perceptron (MLP) type with 10 neurons in the input layer, with 10 neurons in the hidden layer and with 2 neurons in the output layer (Fig. 9).

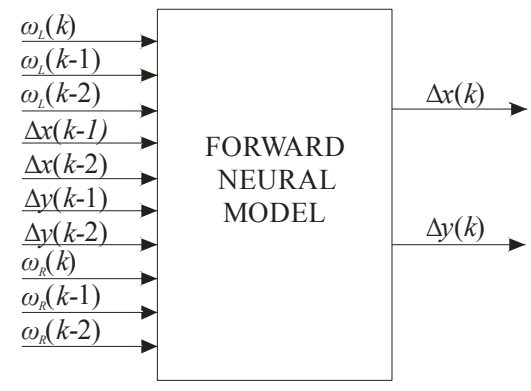

Fig. 9 Forward neural model of mobile robot
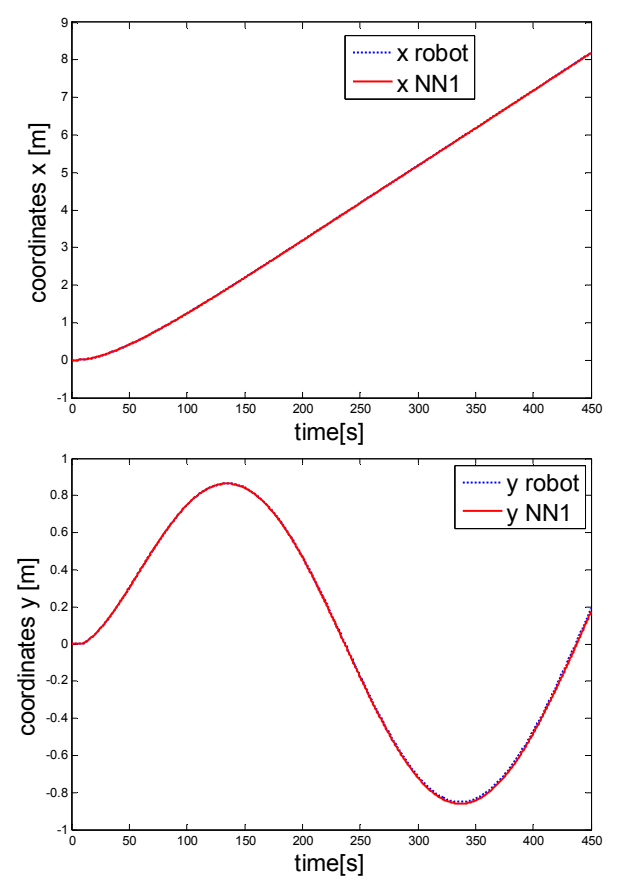

Fig. 10 Comparison outputs of the mobile robot and the forward neural model of mobile robot

ISSN 1338-3957 (online) www.versita.com/aei 
The training of forward neural model is carried out by the Levenberg-Marquardt algorithm using Neural Network Toolbox. Proposed simulation scheme for obtain training data is in [8].

The validation of the neural model is the next step after training of the neural model. The result of testing of trained forward neural model (Fig. 9) is shown in the Fig. 10. Fig. 10 shows that forward neural model can approximate with accuracy, which meets for its further use at the tracking the defined reference trajectory.

\subsection{Inverse neural model of mobile robot}

To obtain inverse neural model of the system is an important part of the theory of control. If the forward neural model was described by the equation (7), then the inverse model can be expressed in the form:

$$
u(k)=f^{-1}\left[\begin{array}{l}
r(k+1), y(k), . ., y(k-n+1), \ldots \\
\ldots . u(k), \ldots . ., u(k-m+1)
\end{array}\right]
$$

where $y(k+1)$ is an unknown value, therefore it is substituted by the reference value of the control variable $r(k+1)$.

To obtain inverse neural model, we have chosen General training architecture (Fig. 11), which requires a known reference trajectory $r(k)$ (Fig. 5 - system, red square). Signal $u(k)$ is applied on the inputs of structure based on input predictive error with the aim of to obtain a corresponding system output $y(k)$, while the neural network is trained by the error $e_{u}(k)$, which is obtained as the difference of the neural model output $\hat{u}(k)$ and input signal $u(k)$ into the system, [3],[13].

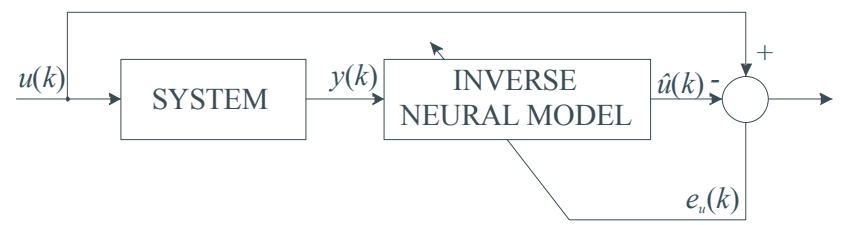

Fig. 11 General training architecture

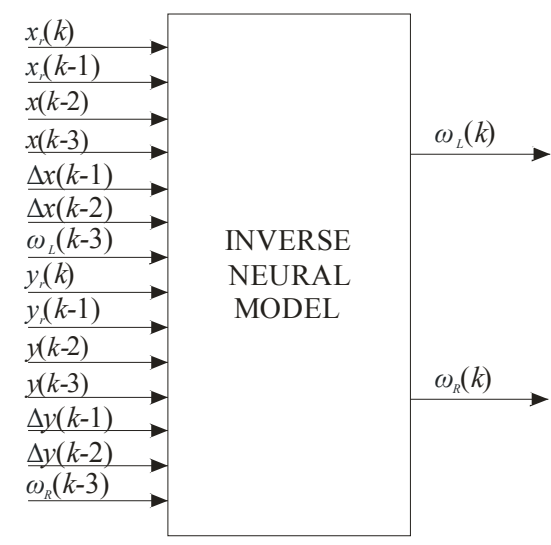

Fig. 12 Inverse neural model of mobile robot

For training the inverse neural model, is used forward neural network of Multi Layer Perceptron (MLP) type with 14 neurons in the input layer, with 5 neurons in the hidden layer and with 2 neurons in the output layer (Fig.
12). Training of forward neural model is carried out by the Levenberg-Marquardt algorithm. Proposed simulation scheme for obtaining training data is in [8].

We applied inverse neural model (Fig. 12) together with forward neural model (Fig. 9) into control structure IMC (Fig. 12), which has been used for tracking defined reference trajectory. Also the IMC filter into control structure for better tracking trajectory is proposed.

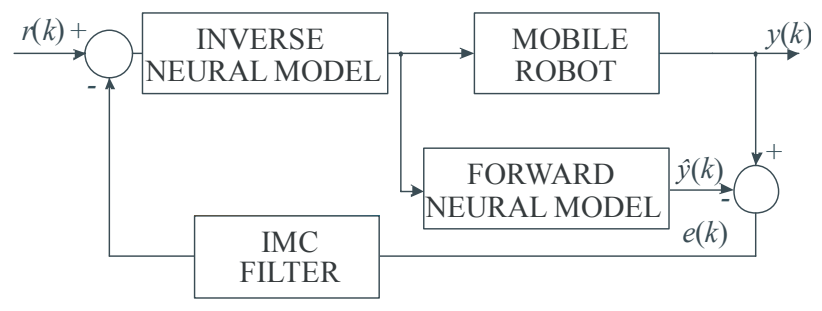

Fig. 13 Control structure Internal Model Control

The output from control structure IMC is current trajectory of simulation model of mobile robot (Fig. 14), which is controlled by nonparametric neural controller.

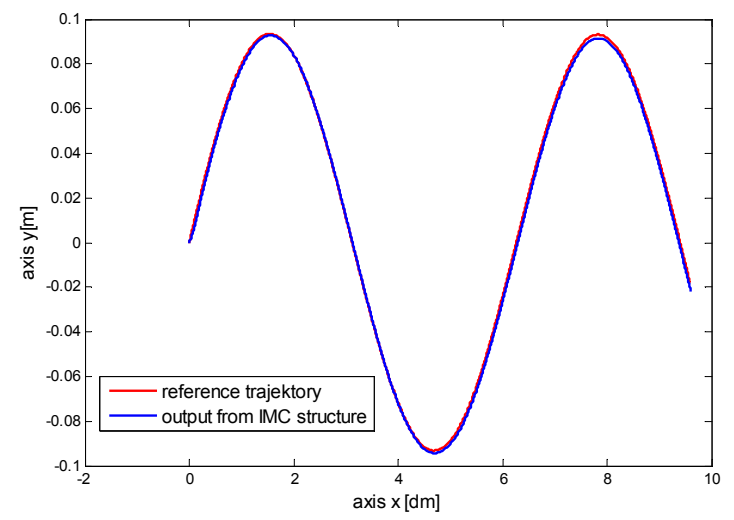

Fig. 14 Resulting neural tracking defined reference trajectory

In Fig. 14 we can see that simulation model of mobile robot tracks the defined reference trajectory type of function sinus. We verified the functionality for other sinus trajectories with other amplitudes. When we want to change trajectory it is necessary to train a new inverse and forward neural model of mobile robot.

\section{CONCLUSION}

In this paper we have discussed the problem of tracking defined reference trajectory of mobile robot. This problem we have been solved by using known methods of classical theory of control by modified approaches of artificial intelligence. The proposed genetic algorithm optimized parameters of PID controller and parameter of speed of rotation $\mathrm{K}$. The obtained optimized parameters then have been applied on simulation scheme of cascade control structure in pursuit track reference trajectory.

The second way as we have solved the task of tracking trajectory was use forward neural networks. We have proposed a forward and an inverse neural model, which we then applied into IMC structure.

The results of our simulations present that either genetic algorithm or neural networks are suitable 
approaches to solve problem of tracking predefined reference trajectory of mobile robot Khepera II. Each of those approaches has its basic advantages - approach of genetic algorithm is universal optimization tool, which can be used for wide range optimization tasks while neural network approach does not need to know physical description of system when its proposing.

From our view it is preferable to use approach of genetic algorithm for solving problem of tracking reference trajectory. In the genetic algorithm, if we want to change the shape of the reference trajectory, just run the algorithm, which generates optimal settings of four parameters $\{\mathrm{P}, \mathrm{I}, \mathrm{D}, \mathrm{K}\}$, while using the neural network we must train the new forward and inverse neural models from new training data, what is more difficult.

We want to use the obtained knowledge in the field tracking reference trajectory of the mobile robot for real mobile robot Khepera III, which is at disposal in our laboratory of Distributed Control Systems in the Department of Cybernetics and Artificial Intelligence.

\section{ACKNOWLEDGMENTS}

This contribution was supported by Agency of the Ministry of Education of the Slovak Republic for the Structural Funds of the EU under the project Centre of Information and Communication Technologies for Knowledge Systems (project number: 26220120020).

\section{REFERENCES}

[1] DOMINGUEZ, D.: VRML and Simulink Interface for the Development of 3-D Simulator for Mobile Robots. Proceedings of World Academy of Science, Engineering and Technology, Vol. 25, November 2007, ISSN 1307-6884.

[2] FIC, J.: Riadenie mobilného robota Khepera II s využitím metód umelej inteligencie. Master Thesis, TU Košice, Faculty of Electrical Engineering and Informatics, Košice, Slovakia, 2009, pp. 67.

[3] JADLOVSKÁ, A. - SARNOVSKÝ, J.: Aplikácia inverzného neurónového modelu nelineárneho procesu $\mathrm{V}$ štruktúre priameho inverzného riadenia. AT\&P Journal, 2002, No. 10, pp. 75-77, No. 11, pp. 84-86, No. 12, pp. 46, 2002, ISSN 1335-2237.

[4] KÜHNE, F. - LAGES, W. F. - GOMES da SILVA, J. M.: Mobile Robot Trajectory Tracking Using Model Predictive Control. In.: Proc. of the 2005 Latin-American Robotics Symposium, São Luís, Brazil, September 2005.

[5] K-TEAM, http: <http://www.k-team.com>

[6] GAJDUŠEK, M. - ŠOLC, F.: Generovaní časově optimální trajektorie pro mobilního robota $\mathrm{S}$ diferenciálním řízením. AT\&P Journal, 2006, No. 2, pp. 86-89, ISBN 1335-2237.

[7] MASÁR, I.: Inteligentný regulátor na sledovanie trajektórie mobilným robotom. Automatizace, 2007, No. 2, pp. 80-85, ISSN 0005-125X.
[8] ŠUSTER, P. - JADLOVSKÁ, A.: Neural Tracking Trajectory of the Mobile Robot Khepera II in Internal Model Control Structure. Process Control 2010, Kouty nad Desnou, Czech Republic, 2010, pp. C153-1-C153-13, ISBN 978-80-7399-951-3.

[9] SEKAJ, I.: Evolučné výpočty a ich využitie v praxi. Bratislava-IRIS, 2005, pp.157, ISBN 80-89018-87-7.

[10] SEKAJ, I.: Genetické algoritmy pri návrhu regulátorov a pri statickej optimalizácii procesov, Automatizace, 2004, No. 10, pp. 617-620, ISSN 0005-125X.

[11] JANČOVIČ, M. - ŽALMAN, M.: Návrh regulátora rýchlosti asynchrónného motora prostredníctvom genetických algoritmov, AT\&P Journal PLUS, No. 7, 2005, pp. 64-71, ISBN 1336-5010.

[12] KAJAN, S.: Comparison of Some Neural Control Structures for Nonlinear System. Journal of Cybernetics and Informatics, 2009, Vol. 8, 2009, ISSN 1336-4774.

[13] JADLOVSKÁ, A.: Modeling and Control of Dynamic Processes Using Neural Networks. FEITU, Košice, Informatech Ltd., 173 p., ISBN 8088941-22-9, (in Slovak).

Received October 6, 2010, accepted February 11, 2011

\section{BIOGRAPHIES}

Peter Šuster was born April 19 ${ }^{\text {th }}$, 1985. In 2009 he graduated (MSc) in the field Control Engineering and Automatization at the department of Cybernetics and Artificial Intelligence of the Faculty of Electrical Engineering and Informatics at Technical University in Košice. Since September 2009 he is a PhD student at the department of Cybernetics and Artificial Intelligence. His scientific research is focusing on model of physical systems and proposal of control algorithm using classical and modern methods of control theory.

Anna Jadlovská was born October 29th, 1960. She received her MSc. degree in the field of Technical Cybernetics at the Faculty of Electrical Engineering of the Technical University in Košice in 1984. She defended her $\mathrm{PhD}$ thesis in the domain of Automatization and Control in 2001 at the same University; her thesis title was "Modelling and Control of Non-linear Processes Using Neural Networks". Since 1993 she worked at the Department of Cybernetics and Artificial Intelligence Faculty of Electrical Engineering and Informatics Technical University in Košice as an Associate Assistant and since 2004 she has been working as an Associate Professor. Her main research activities include the problems of adaptive and optimal control - in particular predictive control with constraints for non-linear processes using neural networks and methods of artificial intelligence (Intelligent Control Design). She is the author of scientific articles and contributions to various journals and international conference proceedings, as well as being the co-author of some monographs. 